\section{The Twitter revolution}

Social Media and Politics: Online social networking and political communication in Asia, edited by Philip Behnke. Singapore: Konrad Adenauer Stiftung, 2010. 140pp. No ISBN number.

$\mathrm{T}$

HIS BOOK provides an informative snapshot of where countries in and around Asia are with their technology and how governments are responding. Behnke binds together reports from Pakistan to the Pacific, some of which include analyses of elections such as the 2010 'Twitter election' in Australia, and more conflicting chapters of politics such as the Thai 'Red Shirts' political crisis during 2010, as well as the 2010 Philippine election. Alastair Carthew reports on the tendency of heavy-handed governments such as the previous Thai rulers using Twitter to send quick updates to its supporters while blocking more than 50,000 websites, showing governments are as competent as their citizens when in keeping up with developments and none more so than China and Vietnam. The micro-blogging craze through sites such as Sina Weibo reportedly provided a decent challenge to censors, however Zhai Zheng notes the self-censorship phenomenon as well, where sites comply with government policy and toe the line in a bid to stay online. Zheng

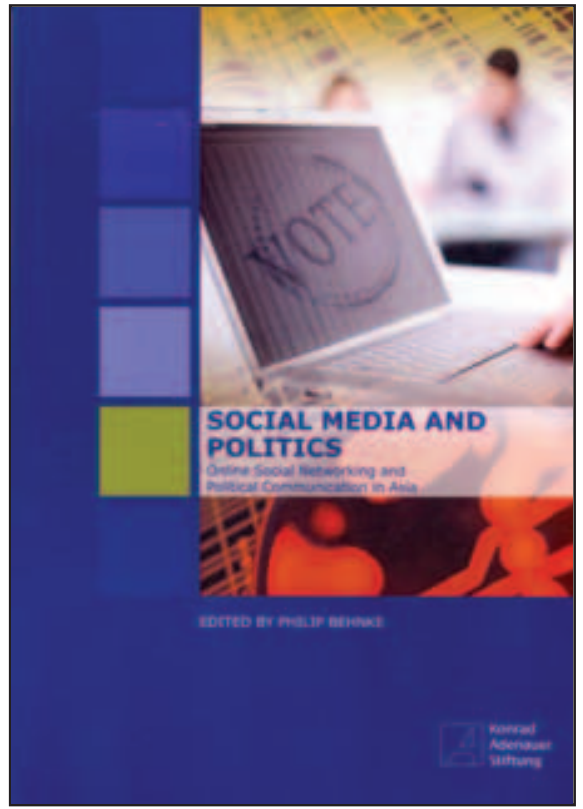

quotes an expert in new media from the School of Journalism and Communications at Peking University, $\mathrm{Hu}$ Yong, who makes the point that a '100 percent Twitter clone won't survive in China. Striking a balance between the country's internet regulations and users' increasing demands for speedy real time information is like tightrope walking.' Just as 'microblogging' is praised for the speedy flow of information, particularly during events such as the Yushu earthquake, Ji-hyun Cho reports that Korea has encouraged the younger and tech-savvy generation to get out to vote-surely a boon for democracy.Artcles in the collection list pages of revealing facts on the 
increasing millions of Asian internet users, even in developing nations. Vietnam's usage grew by 10,882 percent last decade and it looks as though India's usage is set to explode with half of its 1.16 billion people under 25 years of age; a relatively small 16.18 million internet users is going to multiply rapidly in a short time. The research highlights governments are clearly aware of the impact of technology on the dissemination of information. Cambodia's Ministry of Information spokesman is quoted: 'Personal interaction and direct contact with voters will ultimately determine the choices and responses of voters.' Yet others like Vietnam see the need to curtail. Human Rights Watch in 2010 observed that the Government detained bloggers while permitting cyber attacks against anti-government pages. Stephen Quinn's article quotes Vietnam's Prime Minister Nguyûn Tân Dŭng: "The truth is always the truth but we must choose the suitable time to tell the truth to ensure the country's interests.' While the reports provide excellent case studies, many questions remain, such as how deep is the effect on political results? And is it really a revolution in itself or simply an ever-adapting medium? -Alex Perrottet is Pacific Media Watch's contributing editor.

\section{How to be a mojo in Asia}

Mojo-mobile journalism in the Asian region, by Stephen Quinn. Singapore: Konrad Adenauer Stiftung: 2009. 66 pp. No ISBN. E-book at www.kas.de/wf/doc/ kas_18599-544-1-30.pdf

TEPHEN QUINN presents in
this rather concise publication the concept of mobile journalism (mojo) within the Asian context. Along with practical tips on how to be a mojo in this region, Quinn provides cases studies and examples in an anecdotal form from Asia and around the world to support his argument that journalists in Asia need to embrace new technologies and learn how to maximise the use of mobile phones to improve and increase their mobility. The author links his argument for mobile journalism with the rapid growth of mobile and internet use in Asia which contributes not only to further technological advancements in this area but also to an increased demand for more and 'fresher' news. All journalists are potential mojos, although not all will engage with this form of journalism. This approach is more appropriate for the first level of reporting, breaking news. A mojo, according to Quinn, uses a mobile phone to gather and distribute news which can consist of text, audio, stills or video or a combination. 